\title{
Mechanical and electrical properties of a polyester resin reinforced by clay-based fillers
}

\author{
Dorel Buncianu ${ }^{1}$, Nicolas Tessier-Doyen ${ }^{2}$, Fabien Courreges ${ }^{3}$, Joseph Absi $^{2 *}$, \\ Pascal Marchet ${ }^{2}$, Mihai Jadaneant ${ }^{1}$ \\ ${ }^{1}$ UPT Timisoara-Department of Mechanical Engineering, Bd. Mihai Viteazu 300222, \\ Timisoara, Romania \\ ${ }^{2}$ Laboratoire SPCTS, Centre Européen de la Céramique - 12 Rue Atlantis \\ 87068 Limoges cedex, France \\ ${ }^{3}$ Laboratoire XLIM, 123, avenue Albert Thomas 87060 Limoges cedex, France \\ ((Manuscript Received May 13, 2016;Revised September 29, 2016; Accepted November 24, 2016)
}

\begin{abstract}
In this study, composite polymer-based materials, in which a significant proportion of polyester resin has been substituted by low cost and environmentally friendly clay-based raw materials, have been elaborated. The main objective is to improve mechanical properties keeping a reasonable electrical insulating behavior. A homogenized distribution of fillers within the matrix compatible with the processing parameters has been obtained up to a maximum added fraction of $20 \mathrm{vol} \%$. Mechanical characterizations performed with uniaxial traction tests and Charpy impact pendulum machine have shown that stress to rupture can be enhanced of about $25 \%$ and that fracture energy value has double for the best formulations. Dielectric constant decreases and loss factor slightly increases while electrical resistivity remains almost invariable. From a general point of view, composite materials with metakaolin fillers exhibit higher mechanical properties and a greater electrical insulating behavior. Microstructural observations revealed the presence of decohesive agglomerates of particles at the interface with the matrix. Finally, mechanical properties are more sensitive to the homogeneity of fillers dispersion in the matrix than electrical properties.
\end{abstract}

Keywords: Clay-based fillers; Electrical properties; Mechanical properties; Polyester resin.

\section{Introduction}

Incorporation of environmentally friendly fillers in polymer materials is increasingly of interest because of recent European rules (Registration, Evaluation and Authorization of CHemicals) imposed to industrial companies working in chemical industry. That is for this reason that mineral raw materials belonging to phyllosilicates group are interesting candidates in the objective (i) to decrease the overall amount of synthetic polymer production and (ii) to improve mechanical properties of such polymer composites and (iii) to ensure a good electrical insulation. In recent years, polymer based nanocomposites reinforced with clay particles have drawn significant attention [1-2]. This is due to the fact that this type of composites shows substantial improvements in mechanical [3] and electrical [4-5] properties over the unmodified polymer, and therefore, it can exhibit a large potential for highperformance applications.

The aim of this study is to determine both mechanical and electrical performances of composite materials fabricated from a polyester resin reinforced with kaolin-based or metakaolin-based particles. We propose here to investigate the effect of added volume proportions from 0 to $20 \mathrm{vol} . \%$ in the resin matrix. Mechanical properties of the composites have been measured through tensile and fracture energy tests. Electrical properties (electrical resistance, dielectric constant and loss factor) have been determined using an impedance analyzer. In order to make the link with the microstructure of composite materials, the results have been explained in light of observations with a Scanning Electron Microscope (SEM) at microscopic scale.

This paper is structured as follows: section 2 deals with the starting characterization of constituents and describes the elaboration process of the composites materials under study. Section 3 presents experimental techniques of characterization and procedures related to mechanical and electrical properties. Finally, section 4 reports the main results and a discussion is proposed in the last section.

\section{Composite materials: constituents and elaboration process}

\subsection{Constituents}

\section{Polyester resin}

The resin is an unsaturated polyester resin (2S, supplied by PRESI France). The accurate chemical structure is unknown

\footnotetext{
"Corresponding author. Tel.: +33587502387, Fax.: +33587502304
}

E-mail address: joseph.absi@unilim.fr 
but a typical polyester resin exhibits ester groups $(\mathrm{CO}-\mathrm{O}-\mathrm{C})$ and carbon-based reactive sites $\left(\mathrm{C}^{*}=\mathrm{C}^{*}\right)$ within the molecular chain. Thanks to good starting electrical insulating properties and lightness, this thermosetting resin is employed in many applications such as electrical devices, building or navy boat panels. Due to a remarkably low viscosity in the early stage of preparation, a good wettability can be obtained with added particles of mineral raw materials. As a consequence, the concentration of enclosed air bubbles during the processing step decreases significantly. In addition, it exhibits many other qualities such as an excellent adhesion and a low shrinkage. Methyl-ethyl-ketone peroxide and ethanol have also additionally been employed to (i) activate the polymerization and (ii) decrease even more viscosity.

\section{Mineral raw materials}

The clay-based material used as second dispersed phase in the resin matrix is a natural raw material (kaolin BIP, Imerys, France [6]). The weight proportions of oxides and chemical compositions have been determined using ICP (Inducted Coupled Plasma) technique as shown in Table 1. This composition indicates the presence of iron oxide in reduced quantity $(0.26 \%)$ giving a moderate pink color to the powder. As the average dimension of the particles in the starting powder is relatively coarse (about $15 \mu \mathrm{m}$ ), attrition in water (rotational speed of 60rpm during 5h) has been carried out. After a sieving of the mixture $(40 \mu \mathrm{m})$, the particle size distribution has been determined with a laser beam granulometer (Mastersizer 2000, Malvern) as shown in Fig. 1. A dissymmetric bimodal repartition (mean equivalent diameter $\approx 0,92 \mu \mathrm{m}$ ) is observed. The suspension is finally (i) dried at $100^{\circ} \mathrm{C}$ during 3 days in order to remove humidity and (ii) desagglomerated in a planetary grinder. A part of the dried powder is then submitted to a thermal treatment at $900^{\circ} \mathrm{C}$ during $2 \mathrm{~h}$ in order to provoke the dehydroxylation of kaolinite and to obtain metakaolin phase [7]. Indeed, such thermal treatment corresponds to the chemical reaction $\mathrm{Al}_{2} \mathrm{Si}_{2} \mathrm{O}_{5}(\mathrm{OH})_{4} \rightarrow \mathrm{Al}_{2} \mathrm{Si}_{2} \mathrm{O}_{7}+2 \mathrm{H}_{2} \mathrm{O}$, which occurs between 500 and $700^{\circ} \mathrm{C}$. This process leads to disordered metakaolin $\mathrm{Al}_{2} \mathrm{Si}_{2} \mathrm{O}_{7}$ [8]. The temperature of the exothermic transformation of metakaolin into $\mathrm{Al}-\mathrm{Si}$ spinel (or $\gamma \mathrm{Al}_{2} \mathrm{O}_{3}$ ) is $970^{\circ} \mathrm{C}$. Thus the temperature of thermal treatment $\left(900^{\circ} \mathrm{C}\right)$ is low enough to keep the powders in metakaolin form.

The particle size distribution of metakaolin powder (Fig. 2) exhibits a bimodal form with an increase of small particles whose size is around $200 \mathrm{~nm}$. This indicates that the transformation of BIP kaolin in metakaolin has induced a disorganization of kaolinite platelets highlighted by a slight fragmentation of initial particles agglomerates.

Table 1. Chemical composition of starting kaolin powder in wt.\% (H.L.: heat loss)

\begin{tabular}{c|c|c|c|c|c}
\hline Oxide & $\mathrm{SiO}_{2}$ & $\mathrm{Al}_{2} \mathrm{O}_{3}$ & $\mathrm{~K}_{2} \mathrm{O}$ & $\mathrm{Fe}_{2} \mathrm{O}_{3}$ & $\mathrm{MgO}$ \\
\hline Oxide proportion & 48.1 & 36.9 & 1.9 & 0.26 & 0.17 \\
\hline Oxide & $\mathrm{Na}_{2} \mathrm{O}$ & $\mathrm{CaO}$ & $\mathrm{TiO}_{2}$ & $\mathrm{Li}_{2} \mathrm{O}$ & H.L. \\
\hline Oxide proportion & $<0.20$ & $<0.20$ & $<0.05$ & 0.013 & 11.8 \\
\hline
\end{tabular}

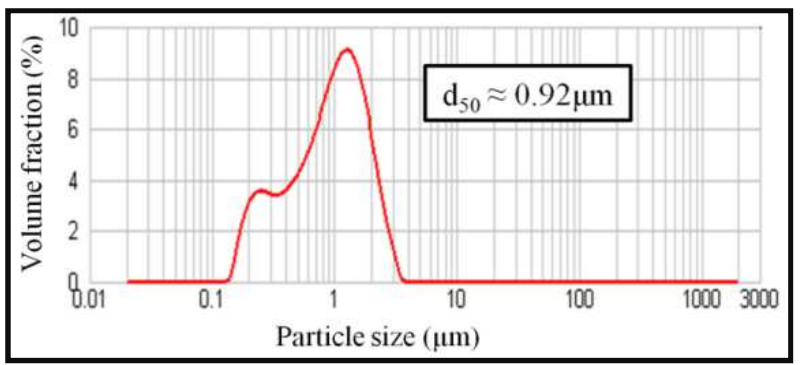

Fig. 1. Particle size distribution of kaolin.

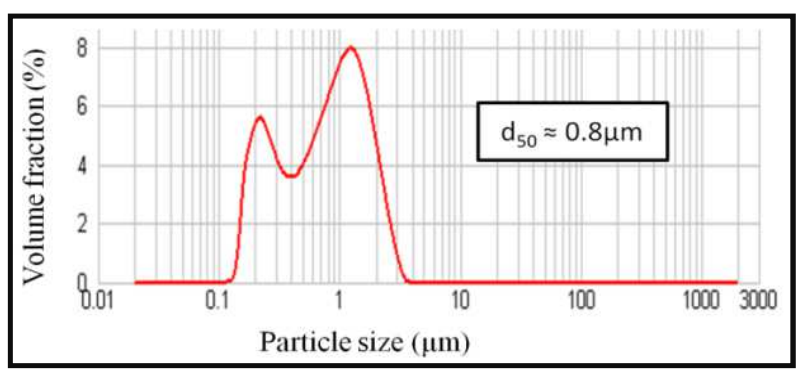

Fig. 2. Particle size distribution of metakaolin

\subsection{Elaboration process}

The first step of the process consists in mixing manually the starting polyester resin powder with methyl-ethyl-ketone peroxide $(4 \mathrm{wt} \%)$ and ethanol $\left(8 \mathrm{wt} \%, 22^{\circ} \mathrm{C}, 1 \mathrm{mn}\right)$. Controlled proportions of mineral powders $(0,5,10,15$ or $20 \mathrm{vol} . \%)$ have been then introduced and slowly mixed during $15 \mathrm{mn}$ in a ultrasonic water bath device (BRANSON 2510). This step allows the removal of air bubbles and ensures a good dispersion of particles. After pouring in an aluminum mold set on a vibrating table $(70 \mathrm{~Hz}-0.8 \mathrm{~mm}$ in amplitude $-10 \mathrm{mn})$ to eliminate residual air, the polymerization occurs at a constant room temperature of $22^{\circ} \mathrm{C}$. Indeed, previous experiments have shown that three days are necessary to reach an almost complete polymerization state. As shown in Fig. 3.a, the lubricated mold contains five slots $\left(170 \times 20 \times 4 \mathrm{~mm}^{3}\right)$ in agreement with the normative rule EN ISO 3167 Type A. The weight proportions of kaolin and metakaolin have been calculated from individual starting powder density values $\left(2.85\right.$ and 2.59 g. $\mathrm{cm}^{-3}$ respectively) and from bulk density of the resin after three days of polymerization $\left(1.16 \mathrm{~g} . \mathrm{cm}^{-3}\right)$ assuming that the amount of mineral particles doesn't affect the polymerization. All samples have been carefully prepared in the same experimental conditions.

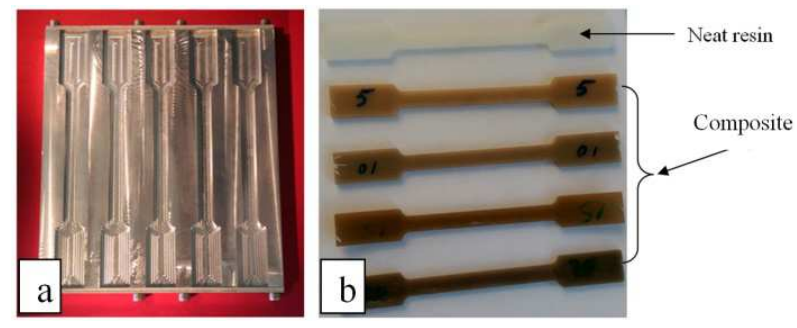

Fig. 3. a) Aluminium mold in agreement with the norrmative rule EN ISO 3167 Type A, b) Demolded specimens after polymerization. 
Table 2. Viscosity values (Pa.s)

\begin{tabular}{c|c|c}
\hline Volume proportion of fillers & Kaolin & Metakaolin \\
\hline $0 \%$ & \multicolumn{2}{|c}{$0.85 \pm 0.08$} \\
\hline $10 \%$ & $1.7 \pm 0.10$ & $1.3 \pm 0.12$ \\
\hline $20 \%$ & $6.5 \pm 0.13$ & $3.7 \pm 0.12$ \\
\hline
\end{tabular}

\subsection{Viscosity measurements}

Viscosity measurements have been performed at $22^{\circ} \mathrm{C}$ using a stress controlled rheometer (AR-G2 type - Texas Instrument(C) operating with a parallel plate fixtures configuration (velocity of 30 RPM). Dynamic viscosity $(\eta)$ has been determined by calculating the slope of the curve representing the shear stress $\tau(\mathrm{Pa})$ as a function of the shear rate $\dot{\mathrm{g}}(1 / \mathrm{s})$. Experiments have been carried out just before pouring the mixtures in the molds respecting rigorously the same time of preparation. Results are reported in Table 2.

Note that for a given proportion of fillers, viscosity of the mixture is systematically greater with the addition of kaolin compared to metakaolin. This is probably due to a greater reactivity with the polyester resin. It can be noticed that the viscosity of mixtures increases significantly when the volume fraction of fillers goes from 10 to $20 \mathrm{vol} \%$. These values explain why higher proportions of filler incorporated in polyester resin don't guaranty the integrity of samples when using the previous experimental procedure (difficulty to remove air bubbles and to suitably disperse mineral particles in the matrix).

\section{Characterization techniques}

\subsection{Mechanical characterization}

\section{Uniaxial traction tests}

Tensile tests were performed at room temperature to determine the maximum strength and Young's modulus of the composite materials in agreement with ASTM D3039 (with a typical speed of the crosshead of $2 \mathrm{~mm} / \mathrm{min}$ ) using a universal testing machine (Lloyd instruments, Bogner Regis, UK). Plotted stress-strain diagrams have been used to estimate Young's modulus (E) values from the elastic response at low strain values (slope of the curve). Five specimens both for kaolin and metakaolin-based composites were tested for each volume fraction.

\section{Charpy impact tests}

Charpy impact resistance through fracture energy $(\gamma)$ was determined with a pendulum machine Type 6545 (CEAST S.p.A, ITALY). The difference between the initial $\left(\mathrm{h}_{\mathrm{i}}\right)$ and the final height $\left(\mathrm{h}_{\mathrm{f}}\right)$ of the hammer (mass $\mathrm{m}$ ) is directly proportional to the amount of energy consumed by the specimen during the fracturing: $\quad \gamma=\mathrm{m} . \mathrm{g} .\left(\mathrm{h}_{\mathrm{i}}-\mathrm{h}_{\mathrm{f}}\right)$

The average total energy of fracture is calculated using 5 specimens $(90 \mathrm{~mm} \times 10 \mathrm{~mm} \times 4 \mathrm{~mm})$.

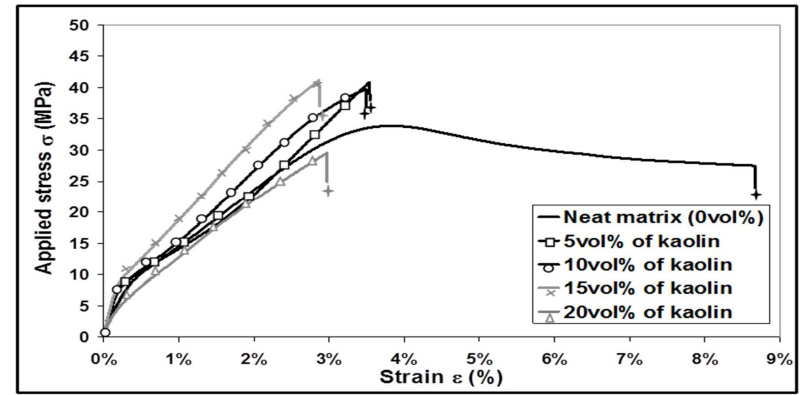

Fig. 4. Tensile stress-strain diagrams for kaolin/polyester resin materials

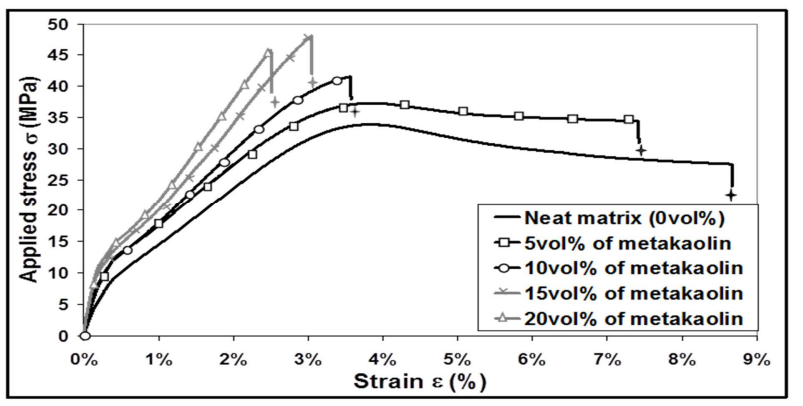

Fig. 5. Tensile stress-strain diagrams for metakaolin/polyester resin materials

\subsection{Electrical characterization}

Measurements of relative permittivity $\left(\varepsilon_{\mathrm{R}}\right)$, loss factor $(\tan \delta)$ and electrical resistance $(\rho)$ were carried out at room temperature with an impedancemeter apparatus (Agilent 4294A). A disk-shaped sample $(13 \mathrm{~mm}$ in diameter and about $2 \mathrm{~mm}$ in thickness) is coated with a conductive layer in order to obtain a capacitor. The sample is then submitted to an electrical AC voltage with an imposed frequency $(100 \mathrm{~Hz}-1 \mathrm{MHz})$. The generated AC current is then measured against the frequency. The device determines for each frequency (i) the ratio current/voltage corresponding to the impedance and (ii) the phase angle between current and voltage. Then, $\varepsilon_{R}, \tan \delta$ and $\rho$ are deduced from the complex admittance using an electrical equivalent model. A parallel RC circuit is the conventional model used for dielectric materials: $\quad \mathrm{Y}=1 / \mathrm{R}+\mathrm{jC} \omega$

\section{Results}

\subsection{Stress-strain diagrams and Young's modulus}

In the case of kaolin incorporation, Fig. 4 shows an elastoplastic behavior of the single matrix without fillers highlighting a high yield strain $(\approx 9 \%)$.

Table 3. Young's modulus values (GPa)

\begin{tabular}{c|c|c}
\hline Volume proportion of fillers & Kaolin & Metakaolin \\
\hline $0 \%$ & \multicolumn{2}{|c}{$3.5 \pm 0.3$} \\
\hline $5 \%$ & $3 \pm 0.2$ & $3.1 \pm 0.2$ \\
\hline $10 \%$ & $3.4 \pm 0.4$ & $3.5 \pm 0.3$ \\
\hline $15 \%$ & $2.6 \pm 0.2$ & $3.8 \pm 0.4$ \\
\hline $20 \%$ & $2.3 \pm 0.2$ & $3.3 \pm 0.3$ \\
\hline
\end{tabular}


When kaolin particles are gradually incorporated, the yield stress to rupture increases up to $15 \mathrm{vol} \%$ and decreases after (20vol\%) showing lower performances. Concerning the strain values, after a high value observed for the neat matrix, a significant decrease is observed for the other samples containing different values of filler volume proportion. Values are situated between $3 \%$ and $3.5 \%$. For specimens with metakaolin fillers, stress to rupture is systematically higher than this of the neat polyester resin matrix (Fig. 5). Note that, the maximum value is observed in the case of $15 \mathrm{vol} \%$ followed by a decrease in the case of $20 \mathrm{vol} \%$. This behavior is similar to that observed in the case of kaolin.

Concerning the strain values, for $5 \mathrm{vol} \%$, the behavior is almost the same as that of single matrix. A significant decrease is observed for the other samples (between 10 and 20vol\%). Values are situated between $2.5 \%$ and $3.5 \%$. After exploring the elastic domain appearing in Figures 4 and 5, the Young's modulus values are reported in Table 3. It can be observed that the addition of a slight proportion $(5 \mathrm{vol} \%)$ of fillers (kaolin or metakaolin) provokes a decrease of Young's modulus. When the added proportion is higher, values of elastic properties remain almost constant for metakaolin addition, while they slightly decrease for kaolin.

\subsection{Fracture energy}

Fracture energy has been determined for different fillers volume fractions (see Fig. 6). Note that values have been normalized with respect to the value obtained for the pure polyester matrix $\left(\gamma_{0}=6.5 \mathrm{~kJ} . \mathrm{m}^{-2}\right)$.

In Fig. 6, fracture energy reaches the highest values when the amount of added mineral particles is $15 \mathrm{vol} \%$. It is indeed multiplied by a factor two with metakaolin. For a proportion of fillers equal to $20 \mathrm{vol} \%$, a decrease can be observed.

\subsection{Electrical resistance, dielectric constant and loss factor}

Electrical resistivity (Fig. 7) does not significantly evolve when the filler proportion increases highlighting a high insulating character of each specimen. However, for a given volume fraction, metakaolin leads to less conductive values compared to kaolin. Fig. 8 displays the evolution of the dielectric constant as a function of the filler content.

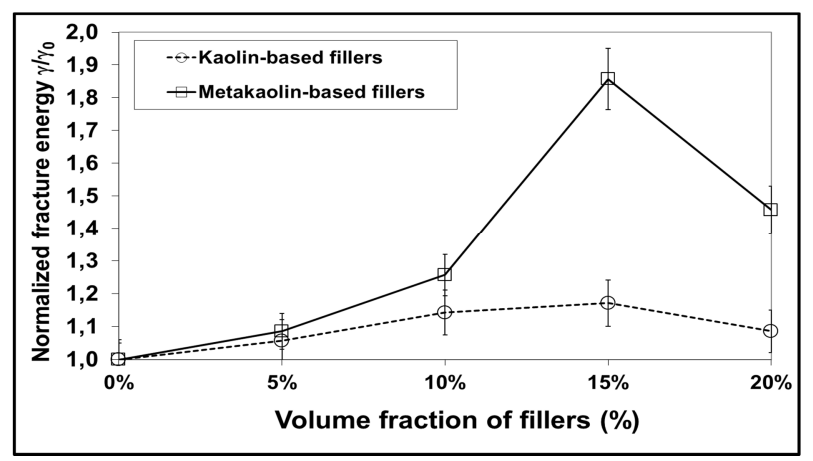

Fig. 6.Variation of fracture energy $v s$ the volume fraction of fillers.

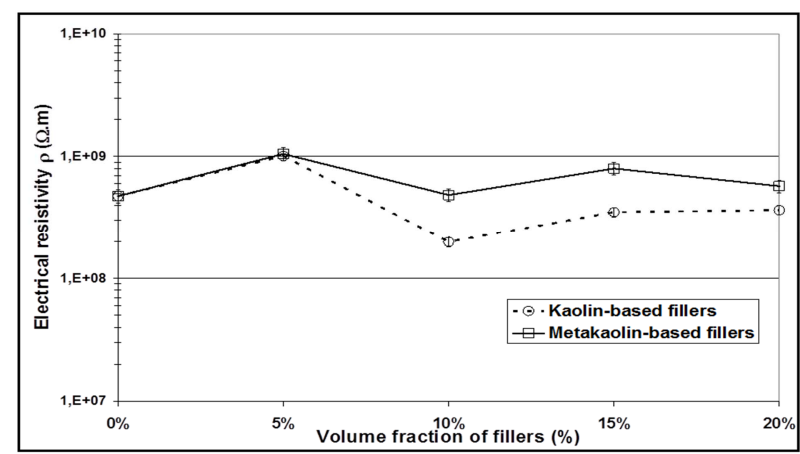

Fig. 7. Variation of electrical resistivity vs the volume fraction of fillers.

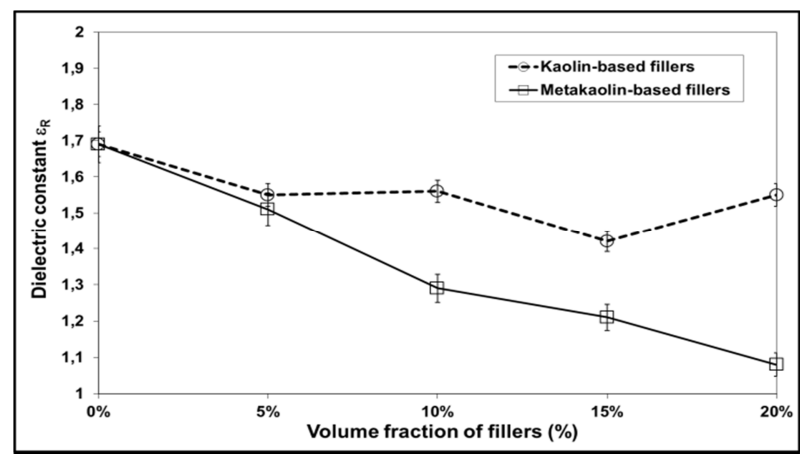

Fig. 8. Variation of dielectric constant $v s$ the volume fraction of fillers.

Logically, the relative permittivity of the composite decreases as the clay-based mineral amount increases. Indeed, the relative permittivity of the filler is lower than the one of the polymer. Thus the measured values decrease with the increasing volume fraction of this second phase. Nevertheless, this decline is greater for metakaolin which is of interest for insulating applications.

Loss factor increases with the volume fraction of kaolin and metakaolin (Fig.9). Logically, the increase of filler volume fraction also implies an increase of the number of interfaces between particles and polymer. With this increase, the space-charge polarization phenomena increase and thus also the dielectric losses. However, the increase is less pronounced with metakaolin addition. From a general point of view, the measured values remain reasonable and interesting for insulating applications.

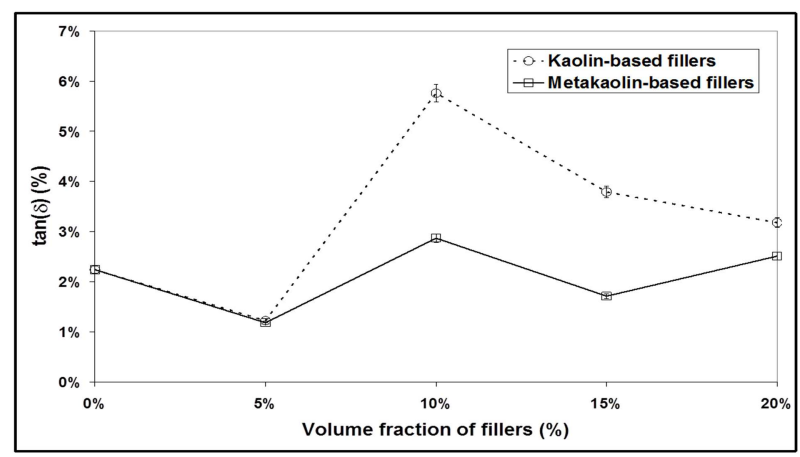

Fig. 9. Electrical loss factor $v s$ the volume fraction of fillers. 


\section{Discussion}

Addition of low cost clay-based mineral materials is in agreement with the expected economic and environmental objectives due to legislation evolutions. In fact, the simple fabrication process allows to elaborate composites material exhibiting interesting properties. Moreover, mechanical and electrical characteristics are sometimes more performant than those of the neat polyester resin matrix.

In this discussion, we analyze both mechanical and electrical characteristics variations in function of the microstructural state. Concerning the mechanical properties, mechanical strength slightly increases and strain to rupture systematically decreases whatever the chemical nature of the fillers (kaolin or metakaolin) and up to $15 \mathrm{vol} \%$. Nevertheless, this is not the case for $20 \mathrm{vol} \%$. This trend is probably due to a perfectible control of the processing (less homogeneity of the fillers dispersion in the matrix). In fact, after breaking of specimens, it is possible to observe the fillers distribution in the fractured section. Scanning electron microscope (SEM) observations (Fig. 10.c) show an agglomeration of the fillers, probably more pronounced in the case of Kaolin addition.

In the case of samples containing $20 \mathrm{vol} \%$ of fillers, some areas of coarse agglomerates whose size is probably increased in function of the fillers added fraction can be easily observed. The presence of decohesions at the interface of matrix and agglomerates seems to be even more pronounced that the size of agglomerates is elevated [9]. Moreover, macroscopic mechanical properties (both fracture energy and stress to rupture) of specimens containing metakaolin are systematically greater. This difference between materials containing kaolin or metakaolin can be justified by hydroxyl groups departure after the previous thermal treatment at $900^{\circ} \mathrm{C}$. Firstly, a better distribution of metakaolin particles in the matrix can be observed in Fig. 10.d corresponding to an appropriate viscosity of the mixture during the preparation. The viscosity is significantly increased with the addition of kaolin compared to metakaolin. This result shows a greater chemical reactivity of kaolin fillers probably due to the presence of $\mathrm{OH}^{-}$groups in the structure of kaolin exhibiting a better affinity with carbonbased groups (ester groups $\mathrm{CO}-\mathrm{O}-\mathrm{C}$ ) of the polyester resin chains. Secondly, a better adhesion at the interface between fillers and matrix is probably obtained with metakaolin.

Concerning the electrical properties, we can observe the following trend: (i) the resistivity values are high enough for insulating applications and doesn't change significantly with fillers volume fraction, (ii) an increase of the volume fraction of fillers implies a decrease of relative permittivity and an increase of dielectric losses. Concerning the resistivity, for a given volume fraction of filler, the addition of metakaolin leads to less conductive values compared to kaolin. This result can be explained by the structure of kao- lin and metakaolin particles respectively. Indeed, study of the electrical behavior of kaolin during thermal treatment revealed that after dehydroxylation and above $700^{\circ} \mathrm{C}$, the only charge carriers remaining are alkali-ions [10]. Such ions can only induce ionic-conduction observed only above $500^{\circ} \mathrm{C}$. Thus, metakaolin presents higher insulating behavior at room temperature than raw kaolin.

Concerning the relative permittivity, the evolution is more pronounced for metakaolin. This phenomenon also corresponds to lower dielectric losses for metakaolin than for raw kaolin. This observation confirms the lower dielectric constant of metakaolin compared to raw kaolin. Indeed, kaolin clays thermally treated at different temperatures $(600$ - $900^{\circ} \mathrm{C}$ ) showed a decrease of the relative permittivity, around two-fold order [10]: the dehydroxylation of kaolinite removed a part of hydroxyl polar groups, thus decreasing the global polarizability of the clay.

\section{Conclusions}

In this study, a polyester-resin and a clay-based raw material were combined in order to fabricate a composite material presenting the following advantages: (i) a reduction in resin consummation balanced by the use of a low-cost mineral raw material, (ii) a simple process of fabrication, (iii) a remarkable improvement of the mechanical and electrical characteristics.

For the two chemical nature of filler (kaolin or metakaolin) and in function of their volume fraction, the composite material presents the following trend of characteristics: (i) an increase of the strength to rupture until $15 \mathrm{vol} \%$ followed by a slight decrease more pronounced for material containing kaolin, (ii) a reduction of the strain to rupture, (iii) an increase of fracture energy up to $15 \mathrm{vol} \%$ followed by a systematic decrease, (iv) a stability of the electrical insulation whatever the added proportion of fillers. Nevertheless, metakaolin addition gives systematically better insulating performances.

This study highlights that metakaolin addition leads to higher mechanical and electrical performances thanks to a better dispersion of fillers in the matrix at the processing step (rather low viscosity when preparing the mixture). Mechanical properties are more sensitive than electrical properties to the homogeneity of fillers dispersion. The variation of mechanical behavior between 15 and 20vol\%, can be attributed to a lack of processing parameters control. This conclusion is evidenced by the presence of coarser agglomerates in the final microstructure due to the increase of viscosity. For further investigations, it would be interesting to increase fillers proportion (up to $45 \mathrm{vol} \%$ ) provided that the elaboration processing is improved by avoiding agglomerates: (i) addition of a fluidizing agent ensuring a low viscosity, (ii) incorporation of mineral powders with thinner particle size distributions (iii) use of vacuum casting to remove residual air bubbles. 


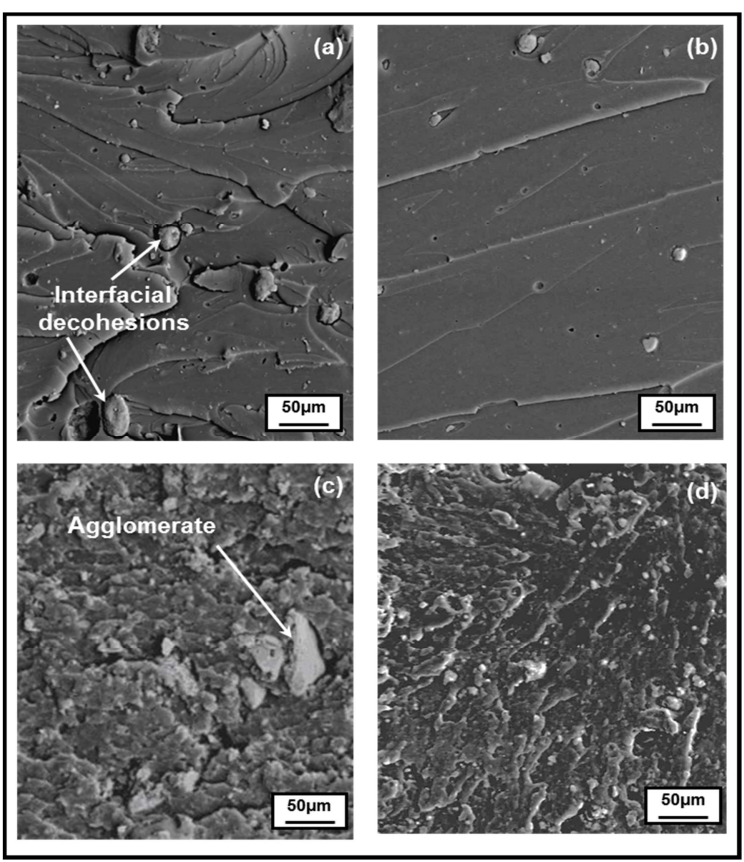

Fig. 10. SEM observations of the microstructure: (a) $5 \mathrm{vol} \%$ of kaolin, (b) $5 \mathrm{vol} \%$ of metakaolin, (c) $20 \mathrm{vol} \%$ of kaolin and (d) $20 \mathrm{vol} \%$ of metakaolin

\section{Acknowledgment}

Authors would like to thank the European Erasmus program for its financial support.

\section{Nomenclature}

$\begin{array}{ll}\eta & : \text { Viscosity } \\ E & : \text { Young's modulus } \\ \gamma & : \text { Fracture energy } \\ \rho & : \text { Electrical conductivity } \\ \mathcal{E}_{R} & : \text { Dielectric constant } \\ \tan (\delta) & : \text { Loss factor }\end{array}$

\section{References}

[1] R. Thomas, D. Yumei, H. Yuelong, Y. Le, P. Moldenaers, Y. Weimin, T. Czigany, and S. Thomas, Miscibility, morphology, thermal, and mechanical properties of a DGEBA based epoxy resin toughened with a liquid rubber, Polymer (Guildf), 49 (1) (2008) 278-294.

[2] D. Devaprakasam, P. V Hatton, G. Möbus, and B. J. Inkson, Effect of microstructure of nano- and micro-particle filled polymer composites on their tribo-mechanical performance, J. Phys. Conf. Ser., 126 (1) (2008), 012057.

[3] J. Baller, N. Becker, M. Ziehmer, M. Thomassey, B. Zielinski, U. Müller, and R. Sanctuary, Interactions between silica nanoparticles and an epoxy resin before and during network formation, Polymer (Guildf), 50 (14) 2009 3211-3219.

[4] S. P. Bao, G. D. Liang, and S. C. Tjong, Effect of mechanical stretching on electrical conductivity and positive temper- ature coefficient characteristics of poly(vinylidene fluoride)/carbon nanofiber composites prepared by non-solvent precipitation, Carbon N. Y., 49 (5) (2011) 1758-1768.

[5] T. Tanaka, G. C. Montanari, and R. Mulhaupt, Polymer nanocomposites as dielectrics and electrical insulationperspectives for processing technologies, material characterization and future applications, IEEE Trans. Dielectr. Electr. Insul., 11 (5) (2004) 763-784.

[6] S. Deniel, N. Tessier-Doyen, C. Dublanche-Tixier, D. Chateigner, P. Blanchart, Processing and characterization of textured mullite ceramics from phyllosilicates, J. Europ. Ceram. Soc., 30 (2010) 2427-2434.

[7] D. Buncianu, N. Tessier-Doyen, F. Courreges, J. Absi, Effect of thermal treatment of a clay-based raw material on porosity and thermal conductivity: experimental approach, image processing and numerical simulation, European Journal of Environmental and Civil Engineering, DOI: 10.1080/19648189.2016.1164086.

[8] R. Podoba, I. Stubna, V. Trnovcova, A. Trnika, Temperature dependence of DC electrical conductivity of kaolin, J. Ther. Anal. Calorim. 118 (2014), 597-601.

[9] S.-Y. Fu, X.-Q. Feng, B. Lauke, Y.-W. Mai, Effects of particle size, particle/matrix adhesion and particle loading on mechanical properties of particulate-polymer composites, Composites: Part B, 39 (2008) 933-961.

[10]Yu K. Shchipalov, V.V. Makarov, T.V. Dubovik, T.A. Vasileva, Dielectric permeability of dehydrated kaolin of various chemical composition, Glass and Ceramics 48 (1991), 809-83.

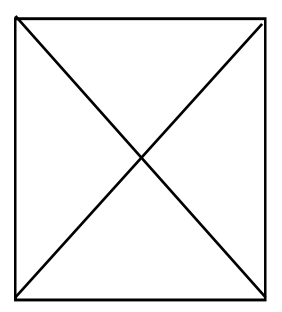

Picture and short bio of less than 100 words should be included. Author's name in Times New Roman 9.5 bold font. Other words in Times New Roman 9.5 regular font. It is recommended that the first and the corresponding authors' bios be included. Others are optional..

\subsection{Author information}

Brief biographies and photos $(25 \times 30 \mathrm{~mm})$ of authors should be submitted after the paper is accepted. The way of writing the author's biography must follow the style below. 